\title{
A Clio Tucidideana entre Maquiavel e Hobbes (as figurações heróicas do historiador) ${ }^{*}$
}

Francisco Murari Pires**

Resumo: $\mathrm{O}$ artigo, tomando por diretriz primeira de sua reflexão a declaração de Césare Ripa que dá Tucídides como nome que emblematiza a escrita da história, e então examinando a correspondente figuração do historiador antigo como paradigma de excelência historiográfica por Jean Bodin, por La Popelinière e por Thomas Hobbes, propõe-se identificar na articulação entre a categoria antiga de herói e a moderna de gênio a intriga conceitual por que responde essa primeira figuração apologética de Tucídides no horizonte do pensamento historiográfico moderno, a qual ganharia foros de apoteose no século XIX com os ditos "Tucidideanos Alemães" (Niebuhr, Ranke e E. Meyer).

Palavras-chave: Tucídides. Historiador. Historiografia moderna.

\footnotetext{
*Versão de texto composto em inglês como capítulo da obra organizada por Christine Lee e Neville Morley, A Handbook to the Reception of Thucydides, Wiley-Blackwell (forthcoming 2014). O texto condensa os teores desenvolvidos em livro a ser editado em 2014 pela Editora Armazém Digital, no qual estão expostos exaustivamente os argumentos e as referências que fundamentam as reflexões condensadas no presente texto.

** Professor Titular em História Antiga pela USP. Atualmente desenvolve projeto de pesquisa Antigos e Modernos: diálogos sobre a escrita da história, com enfoque especialmente dedicado à história das leituras e percepções da concepção de história tucidideana no âmbito da tradição historiográfica moderna, desde o Quattrocento até os inícios do século XXI. Tais abordagens encontram-se editadas na página web: http://www.fflch.usp.br/dh/heros/.E-mail: murari@usp.br.
} 


\section{Introdução}

Desde o princípio, com Heródoto, o dilema da historiografia configura-se: relatos verídicos contra mentirosos, isentos contra parciais, como firmar a dignidade da história por que se memorizem as realidades dos feitos, das obras e dos modos com que nela agem os homens? Porque as histórias se contam tendo em vista um público a que são dirigidas, como deve o historiador conformar modos narrativos que assegurem conviç̧ão de veracidade para as coisas que ele relata como fatos reais? Que virtudes excepcionais the são exigidas por recomendação de preceitos e deveres que consagrem a autoridade de sua narração?

Mas a apreensão da verdade do fato unívoco, adverte Tucídides, é obra penosa. Reclama ingente empenho de inteligência para resolver a aporia intrínseca de sua consecução, pois, para tanto, o historiador defronta-se com a dialética inconciliável dos relatos conflitantes apresentados pelos que presenciaram os acontecimentos e, consoantemente, os informaram. Supõe sujeito humano dotado de espírito superior, distinguido por excelência de plena maturidade experiente que a razão capacita, de modo a poder discernir toda a verdade que desaparece confundida por essa dialética informativa. Via de trajeto difícil, percurso penoso de ingentes trabalhos, restrito a um único caminho que conduz justo à descoberta da verdade do fato. Via de conhecimento histórico própria a um destino pessoal heróico por areté de intelecto excepcional, privilégio de um indivíduo cujo nome chancela a obra por seu primeiro termo declarativo: Tucídides de Atenas. (MURARI PIRES, 1997, p. 286-291; 1998, p. 12-15; 2003a, p. 107-112; 2006a, p. 70-72; 2009, p. 98-101; 2010a, p. 9-18; 2010b, p. 274-276).

Similarmente o dá a entender Luciano listando o acúmulo de virtudes reclamadas pelas quais se almeje escrever história excelente. Ser historiador requer tanto pessoa provida de complexo de virtudes excepcional por domínio absoluto de paixões, (res)sentimentos e (des)afetos, quanto indivíduo cuja situação no mundo pode mais propriamente ser dita inexistencial, pois intriga pertinência a um lugar, dito a-polis, que antes o desvincula do mundo humano ${ }^{1}$, situa-o fora porque, acima dele, sobrepairando as histórias de seus acontecimentos, como o olhar de Zeus. Ideal que, pois, configura persona 
de qualificação divina, na medida em que se concebe sua ideia por atributos definidos por negação de modos e aspectos inerentemente humanos (LUCIANO, 2001, p. 41).

No horizonte do pensamento antigo, a categoria do beróico responde por essa (con)fusão de humano com divino, porque ganha inteligibilidade a projeção de tal persona de historiador ideal. Nesse sentido, a distinção de dignidade historiográfica figurada por Tucídides aproxima-o propriamente da excelência de arte discursiva nomeada conceitualmente Nestor. Especialmente na cena da querela entre Agamêmnon e Aquiles, a figura do venerando conselheiro atua em função judicante, pois discerne a decisão que acerta a dialética das (des)razões de duas partes em conflito. Similarmente a como também o poeta memoriza na cena do escudo de Aquiles, conselheiro vale por histor.

$\mathrm{Na}$ intriga dessas heranças entre epopeia e história, o historiador então figuraria, correspondentemente a Nestor, apreciado como conseIheiro, o juiz cuja narrativa dos fatos acontecidos acertados univocamente a superar a dialética conflitante dos relatos parciais e comprometidos que os contaram. Por esse nexo de fundo homérico de que deriva a historia, o ajuizamento da veracidade do fato responde pelo discurso sapiencial que reitera os preceitos da ordem política por modos nestorianos de saber historiante, assim heroicizante.

\section{Clio Tucidideana}

$\mathrm{Na}$ Iconologia (Roma, 1603), Cesare Ripa define Clio pela conjugação de três ícones por que se a represente imageticamente: uma coroa de louros à cabeça, uma trombeta segura pela mão direita e um livro pela esquerda. Ao fundamentar os nexos de tal configuração iconográfica, Ripa aponta, primeiro, as significações etimológicas que as denominações gregas comportam: ou louvor ou gloria, quer a dos homens que os Poetas pelo canto da Musa celebram, quer a deles mesmos, poetas, porque justamente os gloriam. Diz também as razões da semântica porque se recomenda tal imagética por Clio personificada. Pela láurea, assinala-se o destino de perpetuidade que a História enseja aos homens e seus feitos passados epresentes, valendo como as folhas de louro que preservam vivo por 
longo tempo o verdor. Pela trompa, celebram-se os feitos dos homens ilustres, ressoados nos ares a proclamar universalmente sua glória. Mas trompa segura pela mão direita, porque assinale boa fama, pois, se pela esquerda, signo antes reverso, ou de má fama ou de infortúnio. Já pelo livro com que se registram os feitos dos homens, passados e presentes, assinala a história, atributo dessa Musa. Mas ícone este que comporta uma precisão: o livro é de Tucídides, por nome nele inscrito. A razão de tal privilégio onomástico com que se honre condignamente a história: porque Tucídides, Historiador famoso (RIPA, 1603, p. 346, p. 349 , p. 143 , p. 103 , p. 351, p. 175).

Praticamente contemporânea dessa figuração da Clio tucidideana por Cesare Ripa, La Popelinière firma na Histoire des Histoires (Paris, 1599), similarmente à fama maior de Tucídides, então o intitulando Príncipe da História. (La POPELINIÈRE, 1989a, p. 143). Três décadas antes, Jean Bodin também proclamara no Methodus (Paris, 1566), que não Heródoto, mas sim Tucídides, devesse ser tido por o mais verdadeiro Pai da História (BODIN, 1969, p. 298). Três décadas depois, Thomas Hobbes, em sua tradução dos Eight Books of the Peloponnesian Warre (London, 1629), ao dizer porque a escrita da história alcançara o ápice com Tucídides, consagra fórmula de similar fama historiográfica, mas já por teores reflexivos mais precisamente direcionados: "[...] the most politic historiographer that ever writ" (HOBBES, 1975, p. 6-7).

Por tais projeções de excelência historiográfica, por que o nome de Tucídides emblematize a escrita da história, a persona do historiador é apreciada por enredamentos de intrigas agonísticas com seus pares antigos. Por uma delas, que avança de La Popelinière a Hobbes, subjaz um agón com Tácito, ou mais precisamente com o tacitismo, avatar de maquiavelismo por fins do XVI. Por outra intriga agonística, agora de Tucídides com Heródoto, remonta-se de La Popelinière a Bodin, por meados do século. E, por Bodin, com as intrigas dessa agonística, pondo em paralelo Tucídides e Políbioº, o diálogo remonta a Maquiavel. À época de Maquiavel, entretanto, havia um século (Quattrocento) que a face de Clio mostrava a fisionomia (historiográfica) de Tito Lívio, justo porque incorporasse a correspondente alma de Cícero. 
Por tais diálogos de modernos e antigos, a evolução da identidade da história entre Maquiavel e Hobbes, ao questionar a figuração liviana que a prendia em moldes estilísticos ${ }^{3}$, promove uma vertente de exemplaridade tucidideana de sua escrita, assim transitando os horizontes do saber histórico dos domínios da arte retórica para os da ciência política.

\section{Maquiavel, historiador odisséico}

Ao longo das análises as quais evoluem no século XX, seja a crítica dos estudos sobre Maquiavel seja sua congênere sobre Tucídides, a associação de um nome ao outro ganha nexos de automaticidade, como se compusessem figuras gemelares, de que a presentificação de uma delas sensibiliza a da outra, de modo a entre ambas ou salientar as semelhanças ou antes apontar as diferenças.

Oscilam, assim, os críticos modernos em ajuizar o alcance preciso da interferência que o diálogo de Maquiavel com o historiador ateniense tivesse na constituição da obra e do pensamento político do florentino. Uns, mais céticos, ou o minimizam a um aporte menos relevante de apenas uma ou outra alusão a conhecimentos de realidades factuais da história antiga que Maquiavel eventualmente conhecesse graças à leitura de Tucídides, ou até mesmo questionam a realidade de um tal diálogo, chegando a acusar sua projeção antes "fantasiosa". Outros, pelo contrário, mais confiantes, empenham-se em indiciar nos textos de Maquiavel a impregnação dos traços que assinalam a presença da memória tucidideana. O fazem tanto, em âmbito analítico mais modesto, para atestar, pela crítica textual de tradição filológica, a maior amplitude daquela dependência de conteúdos históricos conhecidos pelo florentino que seriam derivados do ateniense, quanto para, mais ambiciosamente avançando além da mera exegese erudita de uma Quellenforschung, atrelar também ideias e conceitos políticos do teórico moderno a correspondentes preceitos que levam originariamente a marca do historiador antigo.

$O$ viés dominante desse zelo crítico tradicional concentra seus esforços de acuidade exegética em aferir a justeza, contra a impropriedade, da reprodução maquiaveliana dos informes tucidideanos. 
São quase todos concordes no apontar as imprecisões, os erros, os desvios, as deficiências e mesmo as deturpações com que Maquiavel (des)apreende Tucídides. Consequentemente, põem-se os críticos a aventar que ordens de distúrbios teriam prejudicado o (des)entendimento de Tucídides por Maquiavel: ou porque o citasse de memória; ou porque o conhecesse apenas intermediado por outros textos e autores; ou, pior, porque o retorcesse visando à comprovação de suas próprias teses políticas. Empenhos, por diligentes que sejam em sua perícia crítica, duplamente problemáticos. Por um lado, porque de equívoca historicização, pois, ajuizam a práxis intelectiva de Maquiavel pelo padrão de medida de rigor crítico porque responde a (cons)ciência historiográfica "científica" firmada a partir do século XIX e desdobrada no XX $\mathrm{XX}^{4}$, assim implicando que Maquiavel devesse conhecer (o texto de) Tucídides com o domínio que nós, entretanto, só contemporaneamente consolidamos. Por outro lado, porque camuflam um senso de pertinência analítica, todavia, algo duvidoso, quer porque tenha por desfecho antes controvérsias do que conclusões, quer porque, sobretudo, afirme ambiguamente sua (des)valia ao conscientizar uma problemática confiança na efetividade hermenêutica dessa operação crítica, assim a justificando como mediação analítica para a apreensão de uma inteligibilidade superior do texto, mas, efetivamente, a operando autonomamente, dispondo um fim em si mesma.

Pelas concatenações exegéticas com que os críticos modernos então conjecturam as falas com que Maquiavel (supostamente) dialogasse com Tucídides, a presença da influência autoral transita entre os textos de um e outro imbricando as determinações recíprocas de seus correspondentes pensamentos. De modo que, por esse jogo hermenêutico, a consciência moderna tanto presentifica os aportes tucidideanos nas teorias maquiavelianas quanto, em contrapartida, opera a intriga no sentido inverso, a agora aventar o destino de pensamento político (já) moderno prenunciado pelo historiador antigo. Espécie de teleologia tautológica (e mutatis mutandis) porque tanto, de um lado, aventam-se as (des)heranças tucidideanas de Maquiavel, quanto, de outro, estigmatizam-se os anátemas maquiavelianos de Tucídides. 
Afastando-nos de quaisquer pretensões de assim caracterizar ou a genealogia tucidideana de Maquiavel ou a correspondente teleologia maquiaveliana de Tucídides, a via hermenêutica que seguiremos intenta apenas compor um diálogo em paralelo das concepções de escrita da história em um e outro autor.

A 8 de novembro de 1520, Maquiavel recebia, por intermédio dos oficiais do Estudio Florentino, o encargo de compor "anais e crônicas de Florença", fixados seus estipêndios em cem florins. A ordem provinha de um Médici, Giulio, então cardeal. Anos depois, quer quando da redação do Proemio quer, a seguir, da carta em que dedica as Istorie fiorentine ao (já então) papa Clemente VII, o (novo) historiador de Florença revelava por que nuances ele entendera as intrigas daquela comissão historiográfica que lhe fora encomendada. Os termos oficiais da mesma rezavam: "que eu escrevesse os feitos do povo florentino" (MACHIAVELLI, 1962, p. 65). Desde o início da composição, entretanto, o historiador localiza o foco histórico especialmente induzido por seu precípuo patronato: os (feitos dos) Médici, ancestrais do pontífice, senhores de Florença desde Cosme ao Magnifico Lorenzo. Maquiavel assim a concebera de princípio, e a essa história referia-se expressamente como "sua".

A ordem papal que encomendara aquelas Istorie fiorentini a Maquiavel requeria do historiador dons de delicada perspicácia de juízo historiante por que ele bem satisfizesse às sutis ambiguidades de suas injunções Médici. A intriga patronal, nos termos em que Maquiavel a verte, vem assim formulada: "[...] que descrevesse com justeza os feitos de seus ancestrais de modo que não transparecesse qualquer adulação, pois, se lhe era agradável ouvir louvores verazes, desagradava-o ouvir falsos com o fito de obter favores (MACHIAVELLI, 1962, p. 65-66). A onomasiologia constitutiva da obra pelos nexos que vinculam Maquiavel a Médici complica a axiologia da história. O preceito de sua escrita assim afirmado, ao interditar a adulação, recomenda o louvor que ela desvirtua. Pela sensibilidade do juízo com que mantém este afastado daquela, o historiador tanto preserva a dignidade de seu ofício quanto afiança a veracidade de sua história, dado que não a falsifica por comprometimentos de favores e ganhos escusos. As nuances ambíguas da tão direta quão enviesada ordem papal interpelam a inteligência de 
arte historiográfica dele reclamada. A história dos Médici supõe louvores, ça va de sol? E, todavia, por quais aparências de veracidade os leitores discernem louvores insuspeitos contra adulações indignas em história ativada por nexos que justo assim a compromete(ria)m?

Por todos os modos e recursos da arte retórica, Maquiavel empenha-se em livrar, desde e por princípio, sua história do fantasma de nexos onomasiológicos que prejudicassem a apreciação ajuizante de seu serviço historiográfico: veracidade deturpada por desastrosa adulação, a arruinar-lhe os favores do ofício. A enfrentar as atribulações do desafio, o historiador formula, como contrapartida conceitual da adulação, o procedimento de meritória lisonja que, antes dignificando a história, persuadisse a boa recomendação de seus préstimos. Jogo inteligente de tramas de (dis)simulante adulatio retórica que se completa, por fim, revertendo a incidência do ajuizamento respeitante à (in)veracidade da história, cuja denúncia Maquiavel então faz voltar da (des)figuração de lisura da parte do historiador para a de (des)apreço da parte dos leitores: "Assim, Santíssimo e Beatíssimo Padre, empenhei-me nestas minhas descrições em, não maculando a verdade, satisfazer a todos; mas talvez não venha a satisfazer a ninguém e, se assim for, não me admirarei, pois considero impossivel deixar de ofender a muitos quando descrevemos as coisas dos seus tempos". Por que os tempos descritos pela história envolvem também as (des)razões dos leitores, desvirtua-se a correção de seus juízos consoante a (in)satisfação das precípuas subjetividades que comprometem suas distintas expectativas pessoais: esperam eles da história verdades, mesmo que elas os ofendam, ou preferem mentiras, desde que os honrem? ${ }^{5}$

Ora, na primavera de $1521^{6}$, quando dava início à composição das Istorie fiorentini, Maquiavel foi enviado a confabular com os frades franciscanos em sua sede no mosteiro de Carpi, burlescamente (des)qualificada nas cartas trocadas entre Maquiavel e Francesco Gucciardini como "la Reppublica de' Zoccholi" . Guicciardini então instiga o amigo a que tirasse daquela visita os ensinamentos apropriados de uma experiência fradeira, ambiente em que se respiram fraudes e burlas, advertindo-o especialmente a acautelar-se com o que ele dissesse acerca de seus "maiores", os que então empregavam seus serviços, de modo a não comprometer a fortuna dos anais que então escrevia. Maquiavel responde-lhe que justo assim 
o fazia, bem atento à lição que a cena do regime instituído pelos monges à mesa avivava em seu espírito: as conveniências eficientes do silêncio. Já na primeira carta, a certa altura, Maquiavel revelara ao amigo quais eram os modos por que ele amadurecera os cuidados de sua inteligência nestes novos tempos, então resguardando-se bem melhor contra as mazelas de dissabores e adversidade pessoal que lhe causassem os descontroles eventualmente incriminatórios de suas declarações: "[...] da un tempo in qua, io non dico mai quello che io credo, né credo mai quel che io dico, e se pure e' mi vien detto qualche volta il vero, io lo nascondo fra tante bugie, che è difficile a ritrovarlo"s.

Pelo jogo ambíguo porque ele tanto (des)diz quanto (des)crê seus pensamentos, tanto mais que quando por eles expressa alguma verdade, a torna, todavia, indiscernível porque perdida, confundida em meio a mentiras que a rodeiam, Maquiavel tece o véu retórico com que, embaralhando os registros dos traços identificadores, confunde os comprometimentos de sua pessoa. Discriminação de verdade contra mentiras configura convicção apenas de quem detém o poder da palavra que diz a história, pois se a resguarda oculta pelo segredo do arbítrio e querer (dis) simulado porque o historiador a (in)define. Maquiavel, ao dizer os modos personalizados desse espírito que então o toma nos tempos de composição das Istorie fiorentini, evoca competência estritamente humana de inteligência astuciosa de sua escrita, pois nela se trama um jogo (dis)simulado de verdades e mentiras confundidas.

As figurações de sua arte de historiador, então, guardam equivalência com aquela que Hesíodo afirmava ser o apanágio próprio do poder divino figurado pelas Musas que detêm o mistério do canto historiante enquanto memória narrativa de saber factual: sabemos muitas mentiras dizer simeis aos fatos, e sabemos se queremos dar a ouvir verdades?. Musas, pelas alusões intrigadas pela Teogonia hesiódica, respeitam a entidades que representam aspectos (modos, recursos, circunstâncias, efeitos) de atuação narrativa (épos), assim conceituados por seus respectivos nomes, em histórias (cantos) que celebram (hineiam) o poder (a realeza de Zeus) historiando (mitificando) os fundamentos modelares que conferem autoridade (os feitos etiológicos de fundação). As virtudes que por tal teleologia (co)memorativa as 
qualificam referem atributos pertinentes à conjugação da memória coletiva pelo poder (a posse de Mnemosyne por Zeus em união marital). E guardam também as revelações tecidas por Maquiavel equivalência com a virtuosidade que a Odisseia ${ }^{10}$ distinguia como característica das histórias contadas pela figura nomeada Odisseu ${ }^{11}$ enquanto correspondente excelência heróica de memória narrativa e saber factual: dizia semelhas verdades e mentiras.

Em última instância, a questão da verdade da história narrada no âmbito do discurso mítico, aqui apreciada enquanto narrativa do herói, remete para o arbítrio do sujeito que a narra, em conformidade com a ordem total de seus deveres éticos de honorabilidade nobilitadora. Justo por senso de honra nobilitadora afirmado pelas histórias contadas a entreter e ensinar os agentes do poder que promovem e sustentam as narrativas, fundamentam-se similarmente por Maquiavel os reclamos de justas recompensas e mútuos ganhos reciprocamente intrigados pelos nexos entre figuras régias e historiadores.

\section{Jean Bodin, “O verdadeiro Pai da história”}

Era motivo de perplexidade para Bodin que Cícero tivesse nomeado Heródoto "o pai da História”. Honra indevida porque atentava contra a própria definição da história como narração verídica. Se Heródoto primava por algo era por contar antes fábulas e estórias tanto mais maravilhosas quanto falsas, irreais. Todos, desde a antiguidade, acusaram a inveracidade de suas histórias. A fórmula ciceroniana que glorificava Heródoto era equívoca, pois a proposição do deleite a tirar das narrativas de histórias não pode se sobrepor à expressão da verdade, esta sim imperativa. Pelo contrário, justamente porque não se deixara iludir pelas fábulas míticas consagradas pelos poetas que celebravam as perfeições idealizadas da Idade do Ouro, antes retratando realmente que o passado helênico fora dominado, no princípio, por estado de "selvageria e ferocidade", Tucídides, sim, diz Bodin, pode ser tido por "o verdadeiro pai da História” (BODIN, 1969, p. 298). Para Bodin, então, a fama de Tucídides desloca a de Heródoto na honra de fundador da (genuína) escrita da história. 
Por todo um nexo de figurações virtuosas, Bodin ajuíza a excelência historiográfica de Tucídides. Lembra sua privilegiada condição social, proeminente por riqueza e linhagem régia. Diz de sua experiência e conhecimento da vida pública, atuante como legado em missões mais "pretor" durante a guerra. Aponta seu zelo e diligência por consolidar a veracidade dos acontecimentos narrados por sua história ao promover investigações que os acertassem, nesse empreendimento dispendendo grandes somas a pagar a coleta de tais informes. $\mathrm{E}$ especialmente porque presenciou os acontecimentos como que de "um ponto elevado" (COUZINET, 1996a, p. 285), assim dissociando seu olhar de observador das perspectivas comprometidas com um ou outro lado que desvirtuassem sua percepção. Que não os ajuizou pela distorção imediata dos comprometimentos da parcialidade pessoal foi corroborado pela impassionalidade com que não destratou, por injúrias de modos irados, seus próprios concidadãos que o haviam exilado, pelo contrário, elogiando em sua história quem assim o condenara, Péricles, ao afiançar que de sua liderança dependia a salvação de Atenas na guerra. Quem, então, sentencia Bodin, “[...] não depositaria fé em sua história"? (BODIN, 1969, p. 56).

Os elementos de informes históricos por meio dos quais Bodin argumenta os nexos ajuizantes da excelência historiográfica tucidideana encontram-se também registrados nas compilações que compõem as Vitae, de Tucídides, assim incorporadas às cópias manuscritas que transmitiram o texto de sua obra ${ }^{12}$. Compondo seletivamente esses informes antigos respeitantes a episódios e situações que intrigavam a (im)parcialidade do historiador, Bodin os (re) acerta sempre no sentido de firmar a melhor fama do ateniense. Ora, Bodin identificou Péricles como quem movera a acusação contra Tucídides, equívoco histórico evidente face ao próprio texto do historiador, pois, quando de seu exílio, por ocasião da perda de Anfípolis, Péricles estava morto já há alguns anos. Muito provavelmente, o erro de Bodin deve-se à confusão entre a figura do historiador, filho de Oloro, com a de outro Tucídides, filho de Melésias, este sim exilado de Atenas ao ser derrotado por Péricles na disputa de liderança travada em torno da questão do uso dos recursos financeiros da Liga de Delos para o embelezamento urbano de Atenas. Por esse lapso histórico cometido pela memória histórica, entretanto, 
harmoniza-se o acerto da fama tucididiana, por historiador que, exaltando em sua história a atuação de Péricles, louvara justo quem fosse seu adversário pessoal. Pelo contrário, se aventado Cleonte, o demagogo, como o promotor da ruína política de Temístocles em Atenas, compromete-se correspondentemente a projeção da fama do hiostoriador, por mancha que assim deslustra(ria) sua (im)poluta (im)parcialidade. Por toda a história moderna dessas projeções da fama tucidideana, desde seus inícios pelo Renascimento até fins do século XX, o dilema persiste com os críticos oscilando a fama da virtuosidade contra a da viciosidade historiográfica de Tucídides ao sabor das intrigas de sua dialética narrativa que opõe a figuração por que Péricles é exaltado contra a outra por que Cleonte é denegrido.

Por qual deslize de (re)conhecimento histórico se (des)aprecie a (im)parcialidade historiográfica por que responde a fama de Tucídides, a formulação dela apresentada por Jean Bodin condiz com a valoração do historiador figurado como juiz porque os juristas franceses refletiram sobre a história no contexto das lutas de religião na França de meados do século XVI. Avançando além da representação dominante no horizonte do humanismo renascentista porque o historiador fosse apreciado mormente por sua arte retórica em modo advocatício, busca-se firmar para o saber histórico a autoridade política do discurso que firma a verdade porque a apreende por observação em posição elevada, acima dos contenciosos das partes em conflito que a comprometem. ${ }^{13}$ Também e especialmente Bodin assimila a identidade do historiador pela figura do juir, situado acima das partes, assim contraposta à do advogado que, pelo contrário, assume a (des)razão da parcialidade ${ }^{14}$. Por todas essas celebrações com que Bodin evoca certa seletividade da memória respeitante a Tucídides enquanto ideal ou modelo historiográfico, ela assim comparace em figuração de sabedoria ajuizante, justo similar aos modos da heroicidade nestoriana, que, como histor, resolve os conflitos e divergências por que situada acima dos lados querelantes. ${ }^{15}$ 


\section{La Popelinière, “O Príncipe da História”}

Para La Popelinière, Tucídides é sem controvérsias o Principe da História. Por ele, especialmente, a história firma dignidade de narração que prima pela verdade dos acontecimentos, fundamento por que realiza primorosa valia de discernimento e juízo político. Desprovida da marca da verdade que ordena o discurso intelectivo acerca dos fatos humanos, a história, antes de Tucídides, era corpo sem alma. De Heródoto a Tucídides a história dá passo decisivo, por que então recusa o mítico ou fabuloso tão ao agrado do(s) público(s) a que antes poetas contemplam. Já Tucídides tem na instrução proveitosa da posteridade o verdadeiro propósito por que (se) compõe a história, por ele dita ktema es aei, aquisição de bem permanente, "tesouro" de ensinamentos. Pelo lema tucidideano do ktema, La Popelinière assimila, em sua própria concepção de "história acabada" (bistoire accomplie), as razões por que se vislumbre a valia excepcional desse discurso narrativo, que dizendo os modos da passagem dos homens no mundo com o retorno das mesmas vissitudes atualizando no presente a imagem do passado, ensejem-se as lições de prudência sapiente porque melhor defrontá-las. Contra os poetas e os pintores que, inflados por paixões, perdem as representações que imitam em fantasias inventadas, o bistoriador que Tucídides figura tem por guia a razão, porque investiga e ajuíza a veracidade dos relatos por ele confrontados. Por tais procedimentos de controle e verificação, assegura a herança da verdade humana, provendo aos homens o puro espelhamento de seus atos, ou exemplares ou desrecomedáveis, porque conformem virtuosa fortaleza com que enfrentar os caprichos e artimanhas da existência terrena. Em suma, sentencia La Popelinière: "Tucídides é, e será para sempre, notável exemplo a todos altivos historiadores" (La POPELINIÈRE, 1989a, p. 143-148; 1989b, p. 34-41).

Por assentada fama de justa exemplaridade que a figura historiográfica de Tucídides projete, nem tudo se resolve, adverte La Popelinière, a quem almeje ideal maior, supremo, de história acabada ("histoire accomplie"). ${ }^{16}$ Ideal tanto mais excelso quanto supõe correspondente historiador completo, pleno de dons e virtudes por que se cumprem os deveres do oficio, mormente seu fundamento definidor, a expressão da verdade, sem o que a obra nem sequer merece 
o nome de história. Porque compor a mais bela história jamais vista requer engenhosamente comprender, fielmente reter, ajuizar por boa correção, mais, por fim, bem expressar a verdade com seriedade e eloquência acerca de todas as coisas notáveis respeitantes a todos os Estados, ser historiador pleno pressupõe, associado à correta instrução de primor educativo e indispensável experiência das coisas do mundo, indivíduo dotado de raro e gracioso temperamento, por natureza tão generoso, douto, eloquente e judicioso por que se recomende o êxito para tão elevada obra-prima. Caráter, então, de coração bondoso, verdadeiramente nobre e arredio a toda obrigação servil que o desvie, por ponco que seja, de seu dever em menosprezo da verdade, define como homem de bem a condição natural particularmente afeita ao historiógrafo. Ser historiador pleno reclama, por consoante nobreza, vocação que tem por zelo a bumanidade, de que promove proveito e bem comum em menosprezo de vantagens particulares e ganhos ocasionais. E reclama, ainda, espírito de filósofo, de condigno modo contemplativo, que concentre no prazer espiritual porque despreza quaisquer outros bens e vantagens mundanas toda sua realização e felicidade pessoal (La POPELINIĖRE, 1989b, p. 135-139).

$\mathrm{O}$ "temperamento" apropriado por que se almeje um assim irrepreensível desempenho historiográfico, a trilhar a senda reta do dever de veracidade, imune aos desvios das paixões, oferendas, aparências e demais perigos porque as afeições o extraviam, reclama a harmonia das capacidades intelectivas de imaginação, memória e entendimento, acertando-se as corretas proporções que equilibram os humores corpóreos e correlatas afeições anímicas. A harmonia na composição dos humores, por estrita simetria e igualdade de proporções de modo a que nenhum deles prepondere e não predomine sua correspondente parcialidade afetiva, configura, pois, qual seja o justo temperamento historiográfico. Por exemplar que fosse a persona historiográfica de Tucidides, a tese, todavia, por que La Popelinière firma sua reflexão acerca da escrita da história é contundente e implacável: historiador pleno e, consequentemente, história acabada (bistoire accomplie), primorosa, porque livre de quaisquer faltas ou defeitos que acusem imperfeição, (La POPELINIÈRE, 1989, p. 14-15) “[...] jamais houve, nem mesmo tal que se possa arranjar". E é justo a figura de Tucídides que constitui prova evidente de que bistoriador perfeito, favorecido pela natureza e distinguido por afortunada experiência das coisas humanas, não existe. Pois, já os próprios antigos o combatiam, que, 
embora o reconhecessem Príncipe da história pela verdade primorosa que firmara, também nele acusaram faltas e imperfeições. Laivos de passionalidade o tomaram, porque (des)concertou momentos de sua narrativa aos sabores de seus afetos contra desafetos pessoais. Assim, foi benévolo para com a memória do mestre retórico, Antifonte, poupando sua história da notícia de sua degradação, o traidor da democracia, estigma que selou seu vil destino em Atenas. Inversamente, foi algo maledicente contra Cleonte, seu inimigo, a quem tratou por louco e estúpido (La POPELINIĖRE, 1989a, p. 14-15, p. 144-145; 1989b, p. 19, p. 128-175).

Uma nítida oposição dissocia na esfera do saber o humano do divino. Os homens são caracterizados pela fragilidade do entendimento, pelas incertezas das percepções sensoriais, pela mutabilidade, confusão e variedade das opiniões que captam antes aparências, pela constatação de inevitáveis obstáculos e empecilhos mais consciência das dificuldades cognitivas a estigmatizar o estatuto do saber humano pela ignorância e imperfeição. Os erros aderem às obras dos homens e o máximo a que eles podem aspirar é o falhar menos. Somente Deus, Soberano e potência absoluta, luze água pura, causa última de tudo, é fonte espiritual de sabedoria que jorra eterna. A estima para com o saber humano, entretanto, não se esvai por essa (des)consideração que apenas a contrapõe à onisciência divina. Na Idee de l'Histoire Accomplie, bem se (pre)figuram os nexos de arguentos que sustentam a causa dos Modernos na (futura) Querelle com os Antigos, pois diz da inesgotável mãe natureza, provedora de dons e graças permanentes aos homens, avantajando-os, porque tanto aproveitam-se dos conhecimentos que os predecessores lhes legaram, como os superam ao desvendarem o que eles ignoravam. Na marcha da história, Modernos avançam e ultrapassam Antigos. Estes não devem atuar como freio daqueles, a paralisá-los por princípio de imitação porque eles cultuem estáticos figuras de perfeição em imagens petrificadas. Que nos Antigos e suas obras, então, os Modernos tomem o próprio aguilhão da agonística consoante condigna disputa de aprimoramento virtuoso por que os erros e as faltas dos antecessores se critiquem e concertem pelos que os sucedem. Tal é o generoso combate por que progridem as obras dos homens, assim dito por La Popelinière em correspondência com a boa luta de que falava o mito hesiódico. A perfeição configura prerrogativa do divino. Aos homens respeita apenas o avanço que a persegue 
na infindável faina que aspira a minimizar os erros, pois não há homem tão favorecido pela natureza, nem tão afortunado pela experiência das vicissitudes vividas, que esteja livre de faltas, seja em palavras seja em atos. $\mathrm{Na}$ história, joga-se a (im)potência do espírito humano, razão por que a nova Pandora (historiográfica) se concebe antes como vislumbre final do que disposição do princípio: “[...] ser-nos-á, pois, permitido, procurar por melhor historiador e melhor conformar a história. Pelo menos tentar conduzí-la mais próximo de sua perfeição" (La POPELINIÈRE, 1989a, p. 13-14; 1989b, p. 12-19).

Colocando-se a questão das razões porque quer os antigos quer os modernos não alcança(ra)m a consumação desse ideal da histoire accomplie, La Popelinière aventa uma consideração que instaura certa perplexidade: que as qualidades por nós buscadas no Historiador são tão fáceis que nos falta senão uma reta vontade para tornar nosso poder suficiente em o realizar. Pois, a verdadeira e principal causa da falha não há que buscar seu motivo fora do historiador mesmo, uma vez que está em nosso poder, não ser historiador perfeito, mas tão completo que os mais hábeis tenham ensejo de se contentar e não desejar a mais. Desdobrando a intriga dessa perplexidade, La Popelinière desnuda a chaga que dilacera o corpus da historiografia justo porque corrompe a alma do historiador. Visto que a substância, natureza e objeto principal da história consiste em representar a verdade singela e cândida, jamais um só historiador venceu suas paixões e comandou seu espirito porque a dissesse toda que soubesse, simples, nua e franca. Ora, historiador amante da verdade certamente supõe, como sua condição, figura de destino humano extraordinário, privilegiado por graça rara de desígnio divino, que o dote com a complexão e o temperamento de bumores apropriado a formar firme e rígida bondade natural, justamente destemida, que jamais receie expressar tudo que lhe pareça bom, maldoso, verídico, falso, virtuoso, vicioso, excelente e vil em todas as coisas. Mas requer, também e ainda, figura de caráter firme e impoluto, que não se deixe levar pelas vãs aparências deste mundo que o desviem do reto percurso em que se encontra descaindo por tolas e ruinosas cobiças. A razão por que nem um só dentre os historiadores se manteve firme no percurso a honrar a verdade consoante com seu dever, antes todos tropeçaram, não se deu porque não o pudesse, mas porque não o quisesse ou não ousasse. Não há, portanto, que atribuir a falta de uma História acabada senão propriamente que à nossa voluntária corrupção (La POPELINIÈRE, 1989b, p. 51, p. 147, p. 171-178). 
Todavia, interroga-se La Popelinière, pode haver algo que seja mais cômodo que o querer algo belo e louvável? O que há de mais fácil que escrever o que se deseja, o tornar manifesto e dar a conbecer seja em sua época seja após sua morte? Qual obra seria mais agradável, mais digna de ser amada e assumida por todos os tipos de pessoas que uma boa História? Ora, mas uma tal confluência de poder com querer, essa característica facilidade em deslocar a mentira e dizer a verdade como ato do querer, mera manifestação da vontade, é a prerrogativa que a Teogonia hesiódica representa como distintiva do ser divino das Musas enquanto figuração mítica de memória narrativa e saber histórico factual. Pois elas assim teriam comunicado sua palavra ao poeta: "Pastores agrestes, vis infâmias e ventres só, sabemos muitas mentiras dizer simeis aos fatos e sabemos, se queremos, dar a ouvir revelações" (HESÍODO, p. 26-28). Uma convergência similar de poder e querer conformada em narração de histórias é também a virtude que a Odisseia (XIX v. 203) representa como característica da figura heroica nomeada Odisseu.

Lorenzo Valla diz que a arte de escrita da história se torna tanto mais difícil e delicada quanto o historiador seja testemunha dos próprios acontecimentos narrados em sua obra, pois ele próprio se encontra envolvido nos acontecimentos, de que se suspeite algum seu comprometimento. Historiador primoroso é aquele de quem não se sabe dizer, lendo sua História, de que lado ele estava (VALLA, 2002, p. 76). La Popelinière experienciou algo similar ao que Valla aponta, ele cuja História da França fora envolvida pelas diatribes com que os ministros de La Rochelle a atacaram. O historiador buguenote diz, especialmente em sua carta dirigida a Théodore de Bèze (15 de janeiro de 1581), a razão por que justificava a correção de sua História, fundamentando-a em justo princípio historiográfico: manter neutralidade e indiferença no tratamento expositivo dos desígnios $e$ atos de ambos os partidos em luta (SYPHER, 1961, p. 262).

La Popelinière aponta a fonte do erro que particularmente prejudicava os discursos dos reformados: o extravazamento das paixões nos relatos expositivos dos acontecimentos em que os protestantes atuavam arruinava a convicção da justiça de sua causa, pois ensejava (in)convenientes suspeitas e consequente descrédito porque fossem preteridos e mesmo rejeitados. O mal, por transgressão historiográfica, a ser exorcizado é enfaticamente exposto: os transbordamentos 
das paixões que perdem a razão dos fatos verídicos e arruinam, pois, a credibilidade do discurso. Diagnosticado o distúrbio que desvia o historiador da senda da verdade, La Popelinière acerta a correção de tratamento compositivo, porque a história a siga (cor)retamente: afastar da história as paixões. Por narrativa neutra, isenta de passionalidades faccionais que comprometem a imparcialidade expositiva dos fatos, o historiador pensa fundamentar a justa convicção de veracidade que autorize sua história (SYPHER, 1961, p. 329-332).

Cargas de paixões comprometedoras deixadas fora do relato, elididas pelo historiador que o compõe sob o controle da razão, define a via do método historiográfico por que seguira La Popelinière. E, todavia, a persuasão eficiente que a retórica do método almejava se depara ainda com a objeção que insiste em problematizar também a (pretensa) solução descortinada, de modo que persiste o dilema. Respondendo, pouco mais de dois meses depois, a 29 de março de 1581, à carta que lhe dirigira o historiador porque ajuizasse a correção de sua Histoire de France, Theodore de Béze contrapôs ao argumento de imparcialidade firmado por La Popelinière uma apreciação que justamente o contradizia e consequentemente a negava. Apreciando a narrativa que o historiador dera do massacre de Vassy, Bèze acusa na depuração das paixões que apurasse com precisão o fato justo exatamente o oposto: o historiador tanto emagrecera, descarnara aquele acontecimento de sua substância factual omitindo as circunstâncias necessárias de sua ocorrência porque bem se ajuizasse a injustiça então perpetrada, que isentara de criminalidade o ato, entretanto, assim exorbitante e lamentável. A afirmação da realidade do fato requeria, pelo contrário, a exposição densa, enfática, que em justa correspondência com o que se passara apropriadamente o ajuizasse (SYPHER, 1061, p. 333).

A questão por que Bèze intrigava ainda o proclama de imparcialidade do historiador (SYPHER, 1961, p. 264-165) inqueria o (pres)suposto de sua (des)razão: a narração, por que carregada de passionalidade, necessariamente desintegra a apreensão cognitiva do fato? A expressão do olhar, por que subjetivado por uma dada ótica, não é jamais condizente com a realidade do acontecimento? Se sobrecarregada a exposição pelos comprometimentos das paixões supostamente arruina-se a verdade por excessos acrescidos, sua 
supressão não a prejudica correspondentemente por falta? Por qual modo de procedimento narrativo se acerta a justa (im)parcialidade do relato historiográfico por que se aperfeiçoe a expressão da pura e simples verdade factual? A (im)parcialidade objetivante do fato pelo historiador exclui ou suspende a ética de seu juízo subjetivo?

Conexa à argumentação que recomenda a imparcialidade por que o historiador neutralize a interferência das paixões no ajuizamento que narra os acontecimentos, La Popelinière diz também de outro zelo por ele adotado porque melhor se firmasse a convicção de veracidade de sua história que primara pela isenção e neutralidade narrativa. Porque pretendesse apenas que se ajuizasse a veracidade factual de seu relato independente de qual pertinência ou identificação social o (des)recomendassem, não deu a conhecer aos leitores de sua história nem o nome, partido, condição de vida, país ou religião do historiador que a compusera, desejoso de que assim melhor se conformasse a convicção de sua veracidade (SYPHER, 1961, p. 268-270). O dito de La Popelinière lembra, em boa parte, o congênere de Luciano que similarmente apreciava em seu tratado quais eram as condições particulares exigidas da figura pessoal do historiador que fundamentassem a autoridade de seu relato. Pelo recurso narrativo da mera elisão da onomástica identificadora do historiador, La Popelinière (dis)simula a figuração narrativa de sua persona historiográfica.

Todavia, a onomástica comprometedora também era intrigada pela dedicatória da obra, ofertada à Rainha, Catarina de Médicis, e ao Rei, Henrique III. As mazelas de (des)favores e (des) afetos assim enredadas levantavam contra a obra mais nuvens de suspeitas, especialmente entre os correligionários huguenotes, que não se vexaram de acusar uma história feita sob paga dos mandatários Católicos, contra o que La Popelinière ainda intentava se justificar perante Bèze (SYPHER, 1961, p. 262).

Controlar a palavra descritiva, expurgá-la de todas mazelas e vícios subjetivos, especialmente as adjetivações axiologicamente categorizadoras que (des)qualifiquem agentes e seus atos, então disciplinando o discurso a fim de depurá-lo de marcas vocabulares que (des)velem a presença narrativa do historiador, consubstancia o proclamo de impassionalidade historiográfica, a isenção de afeições 
por que, no entender de Francesco Robortello, deva-se compor a história. A palavra disciplinada, modo de indução retórica por que se afirme a (persuasão da) objetividade do historiador, (pretensamente) não expõe sua pessoa, e assim imuniza sua história contra as (in)conveniências das ofensas (in)desejadas que comprometem sua alegada legitimidade (metodológica).

Ora, tais jogos (dis)simuladores de indiciamentos dos nexos onomásticos perturbadores que enredam historiador e historiados a intrigar os ajuizamentos da (im)parcialidade da história composta, assim aventados tenuemente por La Popelinière, eram justo os que Maquiavel intentara, na composição de suas Istorie fiorentini, argumentar uma resolução persuasiva por meio de uma retórica do método de fundo odisséico. Ter-se-ia, por estas considerações do célebre florentino, a intriga metodológica reversa àquela que Tucídides proclamara enquanto fundamento do método (MURARI PIRES, 2003a, p. 148). Nas tramas reflexivas, pelas quais a arte ou ciência da história joga com os recursos inerentes à retórica, o ideal historiográfico de objetividade de fundo heroicizante nestoriano originado com Tucídides vislumbra, por Bodin, Robortello e La Popelinière que assimilam o historiador pela figuração do juiz, axiomas metodológicos que a viabilizem em obliterando da narrativa as marcas pessoais de seu autor. E, todavia, justo pelo preceito da (ambígua) (im)parcialidade, outros pensadores correspondentemente apontaram a miragem de um tal vislumbre: Théodore de Bèze a questionar La Popelinière, e Maquiavel a desvencilhar-se das diatribes que o comprometessem.

\section{Rumo a Hobbes}

Quando, em dezembro de 1627, os filhos de Trajano Boccalini solicitaram aos "Capi del Consiglio de' Dieci” de Veneza permissão para imprimir os Comentários a Tácito por ele compostos, o privilégio lhes foi negado. A fundamentar essa decisão Donato Morosini dizia que Tácito era leitura perniciosíssima, pois retratara os desmandos de Césares tirânicos, apenas afeitos a delitos e vícios, cuja lembrança inocularia no corpo da república o veneno despótico, destrutivo de todo espírito de liberdade e alma cristã que a fundamentavam. 
$\mathrm{E}$ as companhias modernas que rondavam a obra ressoando seus dizeres tanto mais a incriminavam, tais como Maquiavel e outros, destruidores de toda a virtude política, os quais não passavam de rebentos, galhos da árvore de que Tácito fora a semente. Pelo que, a bem resguardar a virtuosa ética republicana da cidade, Morosini preceituava: deveríamos substituir Tácito por Tito Livio e Polibio, historiadores de tempos mais felizes e virtuosos da República romana, e por Tucídides, que escreveu sobre muitas repúblicas gregas, que vivenciaram vicissitudes consoantes às da nossa. Ao vislumbre do direcionamento periclitante por que avançava a rota historiográfica moderna ameaçada de descair pelos abismos do despotismo e da tirania com "[...] a invasão metodológica do tacitismo porque a política faz ninho na história"17, os espíritos reagiram, nas primeiras décadas do XVII, promovendo, em contraposição, modelos de historiadores de estima antiga, para que se exorcizasse o novo mal, desviando-a daquele destino pernicioso. Configuram, então, recomendações de três vias alternativas, justo condizentes com a tríplice nomenclatura historiográfica assinalada no parecer dos doutos venezianos: ou Tito Lívio ou Políbio ou Tucídides, verdadeiros luminares de republicanismo.

A questão colocou-se também por essa época em meio aos círculos dos giovani venezianos, porque se promovesse a virtuosidade republicana preservada em Tucídides contra a viciosidade despótica disseminada por Tácito. Domenico Molino (COZZI, 1995, p. 383-386) instava seus colegas eruditos para que orientassem os estudos pelas melhores finalidades do civismo humanista. Em carta datada de 19 de agosto de 1622, dirige-se a Jan van Meurs instando-o a que traduzisse Tucídides, apropriado antídoto pelo qual se combatessem os venenos do tacitismo. Todos os que amassem a doce liberdade deveriam ser gratos a Tucídides, o preceptor que guardara tal joia em sua história (CAMBIANO, 2000, p. 216).

Ora, o passo que avança de Tácito a Tucídides, ao que postulava o ideário cívico de Veneza, viria a ser dado por aquela época não entre os flamengos, mas sim por Thomas Hobbes que efetivamente traduziu Tucídides em 1628. Todavia, as virtudes porque agora o filósofo recomendava a fama da Guerra dos Peloponésios e Atenienses, antes a desviavam das sendas do republicanismo por que ansiavam os patrícios venezianos. 
Pela Notícia aos Leitores, Hobbes ressalva as razões que projetam a valia que a História de Tucídides comportava perante seus contemporâneos, especialmente recomendável aos aristocratas integrados à corte dos Tudor. Principia seu argumento referendando a tese do primado dos antigos na proposição dos conhecimentos que compõem os studia bumanitatis, assim definindo, para cada domínio intelectivo, uma singular excelência: Homero para a poesia, Aristóteles para a filosofia, Demóstenes para a eloquência, além de outros. Plêiade de heróis que tripulam a Argos da ciência antiga alcançando os modernos em sua viagem sapiente pelo tempo. Em meio a todos eles, Hobbes reconhece também a fama de Tucídides, ali figurando em nome da história. Por sua obra, a ars historica alcançara a altura de perfeição a que a condição humana pudesse aspirar (HOBBES, 1975, p. 6).

Por quais condições, circunstâncias e disposições respeitantes à veracidade histórica pode Tucídides, pergunta-se Hobbes, conjugar excepcional complexo de fundamentos e virtudes por que compusesse história assim primorosa, a alcançar a perfeição? De desleixos ignorantes da verdade jamais foi vítima. Primeiro porque afastou de sua história o passado remoto, alternativa de tempo histórico que inviabiliza autonomia historiográfica, ficando a veracidade do relato na dependência de eventual contaminação por outrem, e não assegurada por conhecimentos constituídos pelo próprio historiador. E então, assim restringindo sua história aos acontecimentos do presente por ele próprio experienciado, pode coletar, por diligência primorosa e inteligência criteriosa, os informes autênticos dos fatos ocorridos, registrando-os de imediato quando ainda frescos na lembrança, graças a duas ordens de primazias que o distinguiam pessoalmente: honorabilidade conjugada com riqueza (HOBBES, 1975 , p. 17). Sua honorabilidade conjugada com riqueza respondia por origem nobre, condição de berço. O nome de Tucídides designa, pois, conceito de excelência de historia magistra vitae, compêndio luminar de ensinamentos de prudência previdente: "Dado que o propósito principal e próprio da história é instruir e capacitar os homens, por meio do conhecimento das ações passadas, a guardar prudência no presente e previdência face ao futuro, não existe nenhum outro que, humano, o realize com maior naturalidade e plenitude do que este meu autor" (HOBBES, 1975, p. 6). 
Tucídides dispõe primor de historia magistra vitae porque, diz Hobbes, primeiro de tudo, as lições provêm da história mesma, fato de sua natureza própria enquanto narrativa, e não produto artificial incorporado intelectivamente pelo historiador. Tucídides realiza em sua obra a essência mesma que define a história: narrativa dos acontecimentos. O historiador, assim, nem se sobrepõe aos fatos de fora e ao alto da história, inserindo-lhe reflexões discursivas que nela refletem antes o saber de sua própria filosofia moral; nem, tampouco, impõe-se aos fatos, intrometido dentro e no fundo da história, especulando, ao sabor dos caprichos dos movimentos de sua pena.

O historiador, assim, nem se sobrepõe aos fatos de fora e ao alto da história inserindo-lhe reflexões discursivas que nela refletem antes o saber de sua própria filosofia moral, nem tampouco se impõe aos fatos intrometido dentro e no fundo da história, especulando, ao sabor dos caprichos dos movimentos de sua pena, sutilezas de conjecturas à guisa de perscrutar no silêncio dos agentes os segredos recônditos de suas motivações e desígnios. $\mathrm{O}$ historiador, pois, não obra posicionado nem acima nem sob a história nem depois e além nem antes e aquém dela, pelo contrário, a narrativa que dela ele dá a revela em si mesma, a re(a)presenta, dispondo o equivalente discursivo da manifestação inerente de seus próprios fatos.

Por essas razões, e não pelo (des)entendimento das que convencionalmente se imputa aos propugnadores de filosofia moral, a fama de Tucídides é plenamente justa: "[...] the most politic historiographer that ever writ" (HOBBES, 1975, p. 6-7). Tal é precisamente o princípio de excelência porque prima a arte de escrita da história, que não contamina a narrativa com a presença do historiador, quer exposta em preleções digressivas quer dissimulada nos corações dos personagens. Arte, pois, que dele reclama as virtudes da inteligência no discernimento seletivo que ordena a concatenação dos acontecimentos com a mestria perspicaz e consequente de sua formulação expressiva. O olhar de Plutarco (Moralia, 347a) que ajuíza a fama de Tucídides assim alcança e (con)funde-se com e no de Hobbes: "[...] ele torna seu ouvinte um espectador, pois ele situa seu leitor nas assembléias populares e no senado, em meio a seus debates; nas ruas, em meio a suas dissenções; e nos campos, em meio a suas batalhas" (HOBBES, 1975, p. 7; PLUTARCO, 1962, p. 501). 
A valia da história de Tucídides atravessa o tempo porque o proveito das lições experientes do passado atualize-se pelos dilemas (re)vividos no presente. Os traços historiográficos tucidideanos, assim delineados pelo olhar de Hobbes, dizem sua História como excelência de historia magistra vitae, inscrição histórica da prudência e, pois, ciência humanista da política. A Clio tucidideana entre meados do XVI e meados do XVII transitava, pois, sua identidade das diretrizes retóricas da ars historica (re)tomada aos Antigos para constituir os fundamentos modernos da ciência política.

\section{Considerações finais}

Em tempos inaugurais da modernidade, pelo que assim diz Maquiavel ou pelo que similarmente imagina Bruegel em Paisagem com a queda de Icaro (MURARI PIRES, 2001b, p. 102-114), refigura-se o heróico herdado do imaginário da Antiguidade Clássica, sujeitando-se (e mesmo diluindo-se) sua concepção antiga (porque se (con)fundia humano com divino) em termos da "imanência da história" ${ }^{\text {. }}$. Por tais jogos retóricos situando nexos figurativos entre bumano e divino, querer e poder, retomados dos antigos, porque os modernos refletem sobre os dilemas da escrita da história, indecide-se o nexo conceitual que, dizendo da excelência superlativa do historiador, ordena a epistemologia da arte ou ciência do discurso historiográfico, assim vacilante no trânsito entre sua apreensão pelo evanescente conceito antigo do heróico e o moderno do gênio/engenho então apenas florescente.

Por Niebuhr mais Ranke, Wihelm Roscher e Eduard Meyer, compondo o quarteto de historiadores do século XIX que Santo Mazarino qualificou de "os Alemães Tucidideanos", a fama de Tucídides, então "idealizado como historiador perfeito" (MOMIGLIANO, 1983, p. 27), é consagrada por uma espécie de apoteose historiográfica, estimando-se sua história como obra extraordinária, singularmente excelsa, inigualável. Ranke reiteradamente exaltou a figura do historiador ateniense, dizendo-o "mestre da historiografia política" por formulação "exemplar inigualável", considerando-o não apenas como a origem mesma da escrita da história, mas também como seu modelo insuperável: "[...] ninguém pode ter a pretensão 
de ser maior historiador do que o foi Tucídides". Niebuhr, de seu lado, afirmou: “[...] se há alguma autoridade confiável em toda a história, esse homem é Tucídides, cujas palavras podem ser incondicionalmente aceitas, ele que nada diz de que não esteja perfeitamente convencido e que é incapaz de pronunciar uma inverdade a respeito de um amigo ou de um inimigo" (NIEBUHR, 1852, v. 2 p. 420 ; v. 3 p. 103-106). Por tais declarações de júbilo entusiasmado quer de Niebuhr quer de Ranke, revive e renova-se por inícios do século XIX a glorificação fulgurante de Tucídides. Então, os modernos, tendo por missão fundar a ciência da história, o elegeram por modelo supremo, projetando de sua figura uma espécie de apoteose. Para Ranke, Tucídides, assim como Homero para a epopeia e Platão para a filosofia, bem pode ser considerado o gênio da história, a qual, graças a ele, alcançou a perfeiçãa ${ }^{19}$. Niebuhr também assim o ajuíza. Do historiador, diz: "O primeiro real e verdadeiro historiador, no nosso entender, foi Tucídides: ele é o mais perfeito historiador dentre os que já escreveram... o primeiro, o Homero dos historiadores". Para o objeto de sua história, reverberando-lhe o louvor, proclama: "A Guerra do Peloponeso... é a mais imortal de todas as obras, dado que foi descrita pelo maior historiador que jamais existiu" "20. Com e por Tucídides, "[...] a história surge de uma só vez em sua mais alta perfeição" (NIEBUHR, 1852, v.1 p. 211; v. 2, p. 352; v. 1, p. 54). Em suma: o imortal, o divino Tucídides, declarava Niebuhr (NIEBUHR, 1852, v. 2, p. 105). Objeto de veneração cultual, confessava Ranke: “[...] um espírito portentoso, grandioso, diante de quem me ajoelho" 21 .

Com o conceito de gênio então firmado entre fins do século XVIII e inícios do XIX ${ }^{22}$, a moderna concepção "científica" de história inaugurada por Niebuhr e Ranke atualiza esse diálogo epistemológico porque o deslocamento da figura (antiga) do "herói" dê lugar, nos horizontes de suas respectivas sensibilidades de pietismo religioso ${ }^{23}$, à figura (moderna) do "gênio" 24 enquanto parâmetro conceitual que catalisa a apreciação da excelência da práxis historiográfica. Por tais historicizadas figurações conceituais, articula-se a ideia ajuizadora da vocação do historiador consoante à ambígua afinidade versus distância, pelos quais se representem as limitações da condição humana face ao caráter sublime da projeção divina. 


\section{THE THUCYDIDEAN CLIO BETWEEN MACHIAVELLI AND HOBBES (THE HISTORIAN'S HEROIC FIGURATIONS)}

Abstract: The article, taking as the first directive of this reflection the declaration made by Césare Ripa which considers Thucydides as a name that defines the writing of history, and then examining the corresponding figuration of the ancient historian as the paradigm of historiographical excellence made by Jean Bodin, by La Popelinière and by Thomas Hobbes, is intended to identify the link between the ancient category of hero and the modern category of genius the conceptual intrigue by which responds this first apologetics figuration of Thucydides on the horizon of modern historiographical thought, which would have its apotheosis in the nineteenth century with the "Germans Thucydideans" (Niebuhr, Ranke and E. Meyer).

Keywords: Thucydides. Historian. Early modern historiography.

\section{Notas}

1 “ou animal (escravo) ou deus" dissera já Aristóteles (Política, I.1253a).

${ }^{2}$ As reflexões por que conduzimos nossos desígnios analíticos na abordagem dessa agonística historiográfica moderna se afastam da apreciação com que Arnaldo Momigliano teceu esse paralelo polibiano-tucidideano em The Classical Foundations of Modern Historiography (1990, p. 48-49). A mirada à vol d'oiseau por que ele enquadrou a questão, a ponderação redutora de seu ajuizamento por operação de categorias historiográficas teleologicamente retroprojetadas de sua contemporaneidade ou para os inícios da modernidade ou para a antiguidade (bistória política, historiador profissional etc.), mais o estilo argumentativo conferencista de seus ensaios despreocupados das referenciações fundamentadoras de suas teses, tornam problemáticas uma justa ponderação das mesmas, tanto mais espinhosas face à aura de autoridade que envolve sua palavra no domínio da epistemologia historiográfica. Confiram-se, nesse sentido: o estudo de Bruno Hübscher (2010) mais as análises críticas de Guido Schepens sobre as teses de Momigliano sobre o modelo tucidideano da historiografia antiga (PAYEN et al., 2010, p. 121-140).

${ }^{3} \mathrm{O}$ deslocamento do parâmetro da forma narrativa centrada na questão do estilo, de que Tito Lívio era o modelo por excelência, para o do primado do imperativo da veracidade factual, é situado por Igor Melani (2006, p. 154, p. 163 165; confiram-se as referências a Arnaldo Momigliano) em torno dos anos de 1560, pondo em destaque a atuação dos juristas franceses (François Baudouin, Jean Bodin, Henri Estienne e outros) que justamente tinham por foco fundamentar sua ciência no conhecimento da história. 


\section{Francisco Murari Pires}

${ }^{4}$ Confiram-se similares considerações tecidas a respeito da análise moderna do valor "científico" da historiografia de Leonardo Bruni em Modernidades Tucidideanas (MURARI PIRES, 2007, p. 90-100).

${ }^{5} \mathrm{O}$ tópos retórico é análogo ao tucidideano do Discurso Fúnebre de Péricles, já por nós analisado em obra anterior (MURARI PIRES, 1997, p. 287-290), mas que retomaremos, particularmente a partir das questões a serem abordadas mais adiante sobre a concepção de história de La Popelinière.

${ }^{6}$ De 17 a 19 de maio desse ano (MACHIAVELLI, 1984, cartas 269 a 274, p. 518 a 529). Os nexos e implicações dessas cartas com a escrita da história maquiaveliana nas Istorie fiorentini foram explorados por Manuela Doni Garfagnini (2002), porém por um viés hermenêutico divergente do que aqui estamos propondo.

${ }^{7}$ Tamancos ou Sandálias usados pelos frades (BONDANELLA, 1973, p. 136).

${ }^{8}$ Niccolò Machiavelli a Francesco Guicciardini, Carpi 17 maggio 1521, carta 270 (Machiavelli, 1984, p. 522; grifos nossos. Giulio Ferroni destaca esta passagem da carta a Guicciardini como traço caracterizador do pensamento e modo de concepção política maquiaveliana, aproximando-a, por um lado, da tradição de "realismo prático, cômico e popular" da tradição florentina que pela figuração da "mascara" opera o "jogo duplo" da "(dis)simulação" porque (des)vela os nexos imbricados pela (in)consciência de "realidade" versus "aparência"; e, de outro, com "a cultura humanista" de seu tempo, assimilando-a pela figuração do Sileno de Alcibiades concebida por Erasmo de Roterdã (FERRONI, 2003, p. 19-23). Já Marcus Fischer (2010, p. 183) circunstancia esta declaração de Maquiavel mais particularmente ao momento de composição das Histórias Florentinas, de modo similar, pois, ao que estamos propondo.

${ }^{9}$ Teogonia v. 27-28 (pela tradução de Jaa Torrano, ligeiramente modificada). Confira-se a análise do texto hesiódico em Mitbistória (MURARI PIRES, 1999, p. 246-248).

${ }^{10}$ Por meio de similar palavra (épos) por igual aedo (nomeado Homero), analogamente confundido com as mesmas Deusas (nomeadas Musas), que diz-se infundiam-lhe o canto.

${ }^{11}$ Uma figuração odisséica de Maquiavel é também proposta por Ugo Dotti que o intitulou "Ulisses da política". Assim o fez, todavia, qualificando por tal nomeação o espírito de "curiosidade" que instiga e fundamenta o cabedal cognitivo acerca dos modos humanos por que também responde a figura do herói antigo: "la silhouette d'un homme, d'une insatiable "curiosité" sur ses semblables, sur leurs stratégies intentionnelles ou leurs actions réelles et concrètes, d'un profond connaisseur de toute la lourdeur des liens inextricables unissant la tradition et la "morale", d'un homme qui peut à juste titre mériter le titre de véritable Ulysse de la politique (DOT'TI, 2003, p. 14). Por outro lado, considerem-se as teses propostas por Miguel E. Vatter (VATTER, 2000, p. 39) que aprecia a modernidade 


\section{A Clio Tucidideana entre Maquiavel e Hobbes...}

do pensamento de Maquiavel em oposição ao pensamento clássico antigo em termos de inversão de prioridade entre forma e evento, de modo que o primado moderno do evento sobre a forma condiz, em termos homéricos, com privilegiamento do "heróico odisséico", fundado na métis, contra, o "heróico aquileano", fundado na força.

${ }^{12}$ Conhecem-se três: a identificada pelo nome de seu suposto compilador, Marcelino, figura no mais totalmente desconhecida; uma outra anônima; e a sintética notícia constante do léxico de Suidas. Encontram-se transcrições dos textos originais e tradução francesa de todas na edição tucidideana de FirminDidot (THUCYDIDES, 1858-72, p. cxl-clxxvij). Desde o célebre artigo de Wilamowitz (Die Thukydideslegende), tais tradições foram criticamente (des)qualificadas como a Lenda de Tucídides: repertório de (re)criações episódicas inferidas ou especuladas a partir ou dos reduzidos informes biográficos ou das caracterizações de personagens e fatos históricos presentes no próprio texto da Guerra dos Peloponésios e Atenienses (LUSCHNATT, 1970, p. 1087).

${ }^{13}$ Confiram-se os comentários de Igor Melani (MELANI, 2006, p. 51).

${ }^{14}$ Confiram-se as análises e os comentários de Cathérine Seghuier-Leblanc (2003, p. 114-129).

15 Analogamente Igor Melani (2006, p. 171, p. 193-200) entende que a visão positiva, de estilo "apologético", com que Bodin ajuíza a figura historiográfica de Tácito, modelo preferível a Tito Lívio, corresponde à sobreposição bodiniana de seu ideal do "historiador como juiz perfeito". Nesse sentido, a percepção de Bodin sobre os historiadores antigos corresponderia ao horizonte de ideias características dos "politiques" franceses de meados do XVI ("filo-francesas e anti-imperiais, filo-monárquicas e anti-republicanas, galicanas e anti-papais). A associação é também marcada por Lestringant, Rieu e Tarrete (2000, p. 295).

${ }^{16}$ Sobre a concepção de história de La Popelinière, vejam-se especialmente os ensaios de George Huppert (1973, p. 141-156) e de Donald R. Kelley (History as a calling: the case of La Popelinière: Kelley, 1997, p. IV, 773-789). Já o artigo de Miriam Yardeni (1964, p. 109-126) compromete-se por uma abordagem predominantemente de enfoque teleológico, preocupada antes em identificar que proximidades ou distâncias as reflexões de La Popelinière marcam em relação ao desenvolvimento da escrita da história, especialmente por suas configurações consagradas a partir do século XIX.

${ }^{17}$ A formulação é de Giuseppe Toffanin (1921, p. 116).

${ }^{18}$ Confiram-se as proposições de Miguel E. Vatter respeitantes a Maquiavel (VATTER, 2000, p. 9) e de Giulio Claudio Argan concernentes a Bruegel (ARGAN, 1999, p. 462, p. 70-471). Para as intrigas hermenêuticas por que transita a figuração do heróico antigo nas reformulações da retórica discursiva dos modernos, especialmente ao longo do XVI a inícios do XVII (de Guillaume 


\section{Francisco Murari Pires}

Budé a Cervantes), confiram-se especialmente as proposições interpretativas de Timothy Hampton (Writing from History, 1990; Unreadable Signs, 1991).

${ }^{19}$ Vorlesungseinleitungen, Aus Werk und Nacblass IV, p. 256-257 (tradução italiana em Lutero e l'idea di storia universale, p. 232).

${ }^{20}$ Lectures on Ancient History v. 2, p. 54. Confiram-se ainda os ajuizamentos externados acerca dos discursos integrados por Tucídides em sua obra, Life and Letters, v. 2, p. 352.

${ }^{21}$ Apontamento ditado em outubro de 1863 e em novembro de 1885 (SW 53/54, p. 26-31, p. 58-59; WINES, ob. cit., p. 4), citado também por Walter Peter Fuchs, (RANKE, Leopold von - Aus Werk und Nacblass III. Frübe Scbriften, herausgegeben von Walther Peter Fuchs, München-Wien, R. Oldenbourg Verlag, 1973, p. 329).

${ }^{22}$ Rudolf and Margot Wittikower, Born under Saturn.

${ }^{23}$ Vejam-se, neste sentido, os comentários de Georg Iggers, ob. cit., p. 76-80.

${ }^{24}$ Nos termos com que o "jovem Ranke"(Lutero e l'idea di Storia Universale, p. 172173) concebe a figura do "gênio" histórico em suas reflexões dos anos 18161817 ("o verdadeiramente grande", "fiel à tendência da época em consonância com o gênio", manifestação e atuação da "ideia divina" por que se define seu destino "grandioso", desde que "purificado do egoísmo" que antes o "cegasse" de modo a "ignorar ou desprezar" tal finalidade sublime, causa de sua "ruína"), tem-se conglomerado de nexos conceituais que guarda correspondência com condizente discurso por que os Antigos conceitualizaram a figura do herói especialmente apreciada em sua dimensão "hibrística" de desfecho trágico.

\section{Referências}

BODIN, Jean. Method for the Easy Comprehension of History, translated by Beatrice Reynolds. New York: W.W. Norton \& Company, 1969.

BRANN, Noel L. The Debate over the Origin of Genius during the Italian Renaissance. Leiden: Boston: Koln, 2002.

BROWN, John L. The Methodus ad Facilem Historiarum Cognitionem of Jean Bodi. A Critical Study, Washington: The Catholic University of America Press, 1939.

CAMBIANO, Giuseppe. Thucydide en Italie et en France vers le milieu du XVIe siècle. In. Ombres de Thucydide, textes réunies par Valérie Fromentin, Sophie Gotteland \& Pascal Payen, BBordeaux, Diffusion De Boccard, 2010, p. 651-664.

COUZINET, Marie-Dominique. Histoire et Méthode à la Renaissance. Une lecture de la Methodus ad facilem historiarum cognitionem de Jean Bodin, Paris: Librairie Philosophique J. Vrin, 1996. 


\section{A Clio Tucidideana entre Maquiavel e Hobbes...}

DOTTI, Ugo. La révolution Machiavel. Traduit de l'italien par Rebecca Lenoir et présenté par Frank La Brasca, Grenoble: Éditions Jérôme Millon, 2003.

. Niccolò Machiavelli. La fenomenologia del potere. Milano: Feltrinelli Editore, 1979.

DUBOIS, Claude-Gilbert. La Conception de l'Histoire en France au XV Te siècle (15101610), Paris: A.G. Nizet, 1977.

FERRONI, Giulio. Machiavelli, o Dell'Incertezza. La politica come arte del rimedio, Roma: Donzelli Editore, 2003.

FRANKLIN, Julian H. Jean Bodin and the Sixteenth-Century Revolution in the Methodology of Law and History. New York/London: Columbia University Press, 1963.

HENRI ESTIENNE. Introduction au traité de la conformité des merveilles anciennes avec les modernes ou Traité préparatif à l'Apologie pour Hérodote, document éléctronique, Paris: Gallica-BNF, 1995.

HESÍODO. Teogonia. A Origem dos Deuses. Estudo e tradução de Jaa Torrano. 3. ed. São Paulo: Iluminuras, 1995.

HOBBES, Thomas. Hobbes's Thucydides. Edited with an introduction by Richard Schlatter. New Brunswick: Rutgers University Press, 1975.

HUPPERT, George. L'Idée d'Histoire Parfaite. Traduit de l'américain par Françoise et Paulette Braudel, Paris: Flammarion, 1973.

. The Renaissance Background of Historicism, History and Theory 1966, vol. V, p. 48-60.

INGLESE, Giorgio. Per Machiavelli. L'arte dello stato, la cognizione delle storie. Roma: Carocci editore, 2006.

La POPELINIÈRE. L' Histoire des Histoires. L'Idée de l'Histoire Accomplie, deux tomes, Paris: Fayard, 1989. p. 14-15.

MACHIAVELLI, Niccolò. Istorie fiorentine, a cura di Franco Gaeta, Milano: Feltrinelli Editore, 1962.

- Opere. III Lettere, a cura di Franco Gaeta, Torino: Unione Tipografico-Editrice Torinese, 1984.

MELANI, Igor. Il Tribunale Della Storia: Leggere La Methodus Di Jean Bodin. Firenze: L. S. Olschki, 2006.

MUHLACK, Ulrich. Herodotus and Thucydides in the view of nineteenth-century German historians. In. The Western Time of Ancient History, edited by Alexandra Lianeri. Cambridge: Cambridge University Press, 2011. p. 179-209.

MURARI PIRES, Francisco. The Rhetoric of Method (Thucydides I.22 and II.35), Ancient History Bulletin 12.3, 1998. p. 106-112. 


\section{Francisco Murari Pires}

. Mithistoria. São Paulo: Humanitas, 1999.

. A Morte do Heróico. In. ROSENFIELD, Kathrin H., Filosofia e Literatura: o trágico, Filosofia e Política, III.1, Rio de Janeiro: Zahar, 2001, p. 102-114.

. Thucydidean Modernities: History between Science and Art in Brill's Companion to Thucydides, edited by Antonios Rengakos and Antonis Tsakmakis, Leiden-Boston: Brill, 2006, p. 811-838.

. Modernidades Tucidideanas. São Paulo: EDUSP-FAPESP, 2007.

. Machiavel, la cour des Antiques et (le dialogue avec) Thucydide. Dialogues d'Histoire Ancienne, v. 34/1, p. 59-84, 2008.

. La Popelinière et la Clio thucydidéenne: quelques propositions pour (re)penser un dialogue entre L'idée d'histoire accomplie et le ktéma es aei. In. Ombres de Thucydide. La réception de l'bistorien depuis l'Antiquité jusqu'au début du XIXe siècle, textes réunies par Valérie Fromentin, Sophie Gotteland \& Pascal Payen. Paris-Bordeaux: Diffusion De Boccard, 2010a. p. 665-678.

. Machiavel et Thucydide: Le(s) regard(s) de l'histoire et les figurations de l'historien, Cabiers des Études Anciennes, n. 47, 2010b, p. 263-281.

. Jean Bodin, o Methodus e a Clio tucidideana: as figurações heroicizantes do historiador. Varia Historia, v. 28 n. 47. Belo Horizonte, jan./june 2012, p. 189-210.

. Ranke e Nieburh: a apoteose tucidideana. Revista de História, n. 166, p. 71-108, jan./jun. 2012.

NIEBUHR, Barthold Georg. The Life and Letters of Barthold Georg Niebuhr, 3 v., edited and translated by Susanna Winkworth. London: Chapman and Hall, 1852. . Lectures on Ancient History, 3 v., translated from the German edition of Dr. Marcus Niebuhr by Dr. Leonhard Schmitz, Philadelphia: Blanchard and Lea, 1852.

RANKE, Leopold von. Sämmtliche Werke. Zur eigenen Lebensgeschichte. Berlin: Dunkler und Humblot, p. 53-54, 1890.

. Aus Werk und Nachlass III. Frühe Schriften, herausgegeben von Walther

Peter Fuchs, München-Wien, R. Oldenbourg Verlag, 1973. - Aus Werk und Nachlass IV. Vorlesungseinleitungen, herausgegeben von Volker Dotterweich und Walther Peter Fuchs, München-Wien, R. Oldenbourg Verlag, 1975.

Lutero e l'idea di Storia Universale, a cura di Francesco Donadio e Fulvio Tessitore. Napoli: Guida editori, 1986. 
RIPA, Cesare. Iconologia, Roma 1603 [Biblioteca Virtuale On-Line]. Disponível em: <http://bivio.signum.sns.it>. Acesso em: 6 dez. 2007.

SASSO, Gennaro. Machiavelli e gli Antichi e altri Saggi, 55v., Milano: Riccardo Ricciardi Editore, 1987-1993.

SÉGUIER-LEBLANC, Cathérine. "Le Gibier de l'Homme d'Étal". Lecture et Exemplarité de l'Histoire à la Fin du XVIe. siècle en France. Thèse de Doctorat sous la direction de Jean Balsamo: Reims, 2003.

SYPHER, George Wylie. La Popelinière: Historian and Historiographer. Cornell University. Ph. D., Michigan. University Microfilms Inc. 1961, n. 61, p. 6848, 388p.

. La Popelinière's Histoire de France. A case of Historical objectivity and religious censorship. Journal of the History of Ideas, n. 24, 1963, p. 41-54.

WITTKOWER, Rudolf. Genius. Individualism in Arts and Artists. In. Dictionnary of the History of Ideas. Edited by Philip. P. Wiener. New York: Charles Scribner' Sons, v. 2, p. 297-312, 1968.

WITTKOWER, Rudolf; WITTKOWER, Margot. Born under Saturn. New York: W.W. Norton \& Company, 1969.

YARDENI, Miriam. La conception de l'histoire dans l'oeuvre de La Popelinière. Révue d'Histoire Moderne et Contemporaine XI, p. 109-126, 1964.

Autor convidado. 